\title{
Imprentas e impresores mexicanos en el siglo XIX: el caso de "Santiago Sierra, Tipógrafo"
}

\section{Mexicans Printing Houses and Printers in the $19^{\text {th }}$ Century: The Case of "Santiago Sierra, Typographer"}

Jonathan Rico Alonso

El Colegio de San Luis

soreldarren@gmail.com

\section{RESUMEN}

El presente ensayo tiene el objetivo de contar la historia de "Santiago Sierra, Tipógrafo", imprenta fundada por Santiago Sierra Méndez en abril de 1877 en la Ciudad de México y cerrada en mayo de 1878. Además de describir y analizar la lista de los diferentes materiales bibliohemerográficos publicados en esta tipografía, se dan luces de los comienzos del conflicto entre los intelectuales Ireneo Paz y Santiago Sierra Méndez, cuyo desenlace fue el enfrentamiento de ambos en la arena duelística a finales de abril de 1880. Asimismo, se anuncian los grupos literarios que participaron en el establecimiento del segundo hijo varón de Justo Sierra O'Reilly, como el Círculo Literario Gustavo Adolfo Bécquer.

\section{Palabras clave}

Imprentas, impresores, 1870, grupos y asociaciones literarios, Santiago Sierra Méndez, literatura mexicana, Ireneo Paz.

\section{ABSTRACT}

The following work has the aim to narrate the story about "Santiago Sierra, Tipógrafo", printing founded on April 1877 in Mexico City and closed on May 1878. Besides to describe and analyze the different kinds of newspapers and magazines published in these printing, this academic paper discuss on the confrontation between Ireneo Paz and Santiago Sierra Méndez. The end of these intellectual question happened on April 1880. Additionally, the following work announces literary groups who collaborated in "Santiago Sierra, Tipógrafo", for example Círculo Literario Gustavo Adolfo Bécquer.

KEYWoRDS

Literary groups, Mexican literature, Mexicans printing houses, Santiago Sierra Méndez, Ireneo Paz. 


\author{
RECEPCIÓN: 04/03/2019
}

ACEPTACIÓN: 02/05/2019

$\mathrm{E}$ ntre 1877 y 1878, el escritor, periodista, diplomático, docente, divulgador de las ciencias, espírita, médium y traductor Santiago Sierra Méndez (1850-1880) se desempeñaba como vocal de la junta directiva de la Sociedad Espírita Central de la República Mexicana, fungía como primer oficial de la Secretaría del Senado (agosto de 1877-febrero de 1878), ${ }^{1}$ pronunciaba discursos en el Instituto Homeopático Mexicano (10 de abril de 1877), ${ }^{2}$ estaba casado con Tarsila González, hija del general Refugio I. González - uno de los principales propagandistas del espiritismo en nuestro país - ${ }^{3}$ y era dueño de una imprenta que llevaba por nombre "Santiago Sierra, Tipógrafo".

Su negocio, ubicado en el número 7 de la calle de las Escalerillas —actualmente calle de Guatemala, a espaldas de la Catedral Metropolitana- (véase Directorio: s. p.), fue inaugurado en la segunda mitad del mes de abril de 1877; la prensa capitalina, tanto conservadora como liberal, celebró la apertura con frases elogiosas y buenos augurios: "deseamos prosperidades de todo género al nuevo impresor y tipógrafo, señor Santiago Sierra", cuyo nombre y "conocidas dotes [...] son la mejor recomendación del establecimiento" (Morales: 3 y Llanos: 3, respectivamente). ${ }^{4}$

Amén de las notas periodísticas, en El Anuario Mexicano (1878), dirigido por Filomeno Mata, y en el libro Biografias de mexicanos distinguidos (1884) de Francisco Sosa, se habló someramente del negocio del hermano menor de Justo Sierra Méndez. En el primero de ellos, se apuntó de manera indirecta que tanto Páginas Literarias del Círculo Gustavo Adolfo Bécquer como El Mundo Científico — publicaciones de las que me ocuparé más adelante - salían de las planchas de la tipografía de Santiago (El Anuario Mexicano: 244). Por su parte, el autor del segundo, amigo estimado de los hermanos Sierra,

\footnotetext{
${ }^{1}$ Santiago Sierra fue nombrado oficial primero de la Secretaría del Senado hacia el 23 o el 24 de agosto de 1877 (véase Aguilar: 3; Reyes, 1877c: 3; y Ruiz: 1).

${ }^{2}$ El discurso se emitió en ocasión del natalicio de Samuel Hahnemann, médico sajón fundador de la homeopatía. Fue publicado el 1 de mayo de 1877 en La Ilustración Espírita (Sierra, 1877b: 147-149).

${ }^{3}$ Acorde con las actas de matrimonio que he revisado, Santiago Sierra contrajo nupcias con Tarsila González por el civil el 2 de diciembre de 1874 y por lo religioso el 8 de diciembre del mismo año en el Sagrario Metropolitano.

${ }^{4}$ De las historias de la tipografía en México que he podido consultar, ninguna menciona el negocio de Santiago Sierra. Además de su referencia explícita en la prensa noticiosa de la Ciudad de México, el libro Obras monográficas mexicanas del siglo XIX en la Biblioteca Nacional de México: 1822-1900, coordinado por Guadalupe Curiel y Miguel Ángel Castro (1997), registra los materiales bibliográficos salidos de dicha imprenta en 1877. Desconozco si algún libro fue publicado en 1878 .
} 


\section{Imprentas e impresores mexicanos en el siglo XIX}

escribió en sus conocidísimas semblanzas: "Cuando, propietario ya de una oficina tipográfica, [Santiago] se preparaba a coleccionar sus escritos y a emprender nuevos y utilísimos trabajos, viose envuelto en una cuestión periodística y, obedeciendo a su nunca desmentida caballerosidad, encontró una muerte inesperada el día 28 de abril de 1880" (Sosa: 987).

Con respecto a las palabras de este escritor, cabe aclarar que, por un lado, la imprenta cerró sus puertas en mayo de 1878, es decir, dos años antes de la muerte de su propietario, acaecida en duelo con Ireneo Paz; por el otro, hasta donde he llegado a investigar, Chano Sierra, como solían llamarlo afectuosamente sus amistades y deudos, nunca tuvo la intención de reunir su obra, fuera ésta literaria o no. Incluso, su compañero de trabajo y amigo cercano, Rafael de Zayas Enríquez, le reprochó el haber dejado a un lado su faceta como escritor de literatura por dedicarse de tiempo completo al espiritismo y a la divulgación de las ciencias en México:

Chano se ha suicidado, respetemos su memoria[:] se ha avergonzado de sus elucubraciones poéticas; quería quemar la mano con que bosquejó la Caza del tigre [novela inconclusa aparecida en La Guirnalda, 1868, y un fragmento en el primer tomo de El Renacimiento], vaciar el cerebro que soñó las flores de fuego, del cielo, de nieve, etc., etc. [serie de cuentos], y sólo acepta sus controversias con La Voz de México y sus traducciones del hebreo, vía de la lengua francesa[;] su obra maestra, como literato, duerme aún en su cerebro. [...] Hoy no piensa sino en los espíritus más o menos perfeccionados, y su gran deseo es llegar a morirse, para tener el infable [sic] placer de derramar lágrimas de espíritu sobre su cadáver insepulto (Jamapa: 1$)^{5}$

La calle de las Escalerillas, ubicada muy cerca del domicilio particular de Santiago Sierra (número 8 de la calle del Parque Cerrado de la Moneda, justo detrás del Palacio Nacional, entre Corregidora y Academia; hoy calle Soledad) (véase Directorio: s. p.), fue - desde los sesenta de aquella centuria - el sitio donde tuvieron su sede diferentes imprentas y administraciones de publicaciones periódicas. ${ }^{6}$ En específico, en 1877, convivieron a lo largo de esta pequeña vía impresos noticiosos (El Monitor Constitucional y El Federalista), conservadores y católicos (La Voz de México), infantiles (El Correo de los Niños), industriales (El Explorador Minero) y de apoyo al gobierno en turno, como La Época y La Libertad; en estos dos últimos, Sierra ocupó los puestos de director y redactor, respectivamente.

${ }^{5}$ El texto fue publicado en El Eco de Ambos Mundos (11 de agosto de 1874) y reproducido el día siguiente en la primera plana de El Federalista. Jamapa era el seudónimo de Rafael de Zayas Enríquez.

${ }^{6}$ Los nombres de los talleres son: Imprenta de E. Neve (núm. 13), Imprenta de J. Flores (núm. 1), Imprenta de Juan Abadiano (núm. 13), Imprenta de Manuel Castro (núm. 9) e Imprenta de la calle de las Escalerillas (núm. 10). 
Se puede asegurar que el taller del hijo de Justo Sierra O'Reilly tuvo mucha competencia: he contabilizado un total de 26 imprentas activas en la Ciudad de México, entre las que destacan, por su importancia, antigüedad, renombre y número de obras publicadas, la de Ignacio Cumplido, la de Jens y Zapiain, la de Ireneo Paz, la del Comercio Dublán y Chávez, la de José María Sandoval, la del Gobierno en Palacio, la del Gobierno Federal, la de Ignacio Escalante, la de Díaz de León y Santiago White, y las tipografías de J. R. Barbedillo y de El Federalista, ambas localizadas en la misma arteria vial que la de Santiago Sierra. ${ }^{7}$ Acerca del diario El Federalista - en el cual los hermanos Sierra y otros escritores publicaron desde la segunda mitad de 1871 y hasta julio de 1876, fecha en la que se separaron por incompatibilidades ideológicas con Alfredo Bablot, director del periódico-, hay que señalar que no dio aviso alguno de la inauguración del taller tipográfico de su ex redactor, pese a que todavía conservaba en su plantilla de colaboradores el nombre de Santiago Sierra, y nunca dio por terminada a mal su relación con aquéllos. ${ }^{8}$ Quizá fue un descuido de cajista, quizá aún había cierto resentimiento en el aire, pero, definitivamente, para Bablot no pasó inadvertida la apertura de la casa tipográfica de su antiguo compañero de prensa. ${ }^{9}$

Gracias a un anuncio publicitario incluido en la última página del primer número de La Época (1 de mayo de 1877), se sabe que la empresa de Sierra dio cabida a trabajos tipográficos de toda clase: "circulares, tarjetas de visita y de anuncios, esquelas, recibos, libranzas, conocimientos, facturas, estados, periódicos, anuncios y carteles de todos tamaños" (Sierra, 1877a: 4), ${ }^{10}$ con especial atención a obras científicas y libros de texto. Asimismo, se afirmaba que sus precios eran sumamente módicos y se "garantiza[ba] el mayor esmero y pulcritud en las impresiones" (1877a: 4).

${ }^{7}$ La de Barbedillo se encontraba en el número 21 y la de Alfredo Bablot, la de El Federalista, en el 11. En esta lista conté el Establecimiento litográfico de Victor Debray y Compañía, que sacó a la luz aquel año su famosa obra Álbum del ferrocarril mexicano: colección de vistas pintadas al natural. Con respecto al quehacer editorial de Francisco Díaz de León, remito al artículo de Leal (25-43). Sobre los grupos de editores mexicanos del siglo xIx, véase Giron (51-59).

${ }^{8}$ Véanse los siguientes textos firmados por Bablot en El Federalista: "Lo que pasa. El Siglo XIX” (1876b: 2); "El Federalista. Cambio de redacción" (1876a: 1), y "El Federalista. Breves palabras" (1876c: 1).

${ }^{9}$ Para más información al respecto, véase Rico (2019).

${ }^{10}$ Tarjeta (de visita): "estampa pequeña, con el nombre de alguno, que se deja en la casa de aquel a quien se ha ido a visitar, o se remite para cumplimentar a alguna persona por cualquier motivo"; libranza: "orden de pago que se da, ordinariamente por carta, contra aquel que tiene fondos o valores del que la expide"; conocimiento: "papel firmado en que uno confiesa haber recibido de otro alguna cosa, y se obliga a pagarla o volverla"; estado: "el resumen por partidas generales que resulta de las relaciones hechas por menor, que ordinariamente se figura en una hoja de papel; como un ESTADO de las rentas del vecindario, del ejército, etc.” (RAE, 1869). 


\section{Imprentas e impresores mexicanos en el siglo XIX}

En su artículo "Libros de texto", Sierra revela la razón por la cual le prestó un cuidado singular a las obras escolares:

La ciencia necesita en México de dos poderosos estímulos: la formación de libros de texto por los profesores de las escuelas, relegando los extranjeros al rango de obras de consulta; y que el Estado subvencione con mayor generosidad los gabinetes y laboratorios, aumentando en lo posible y paulatinamente el sueldo de aquellos catedráticos que más renombre alcancen por sus invenciones y descubrimientos (1877g: 150). ${ }^{11}$

En 1877, el autor de estas palabras — que había dejado de escribir literatura y se había desempeñado como profesor de historia y de geografia en escuelas municipales - sabía que nuestro país requería de mayores impulsos y alicientes para que continuara el progreso en las ciencias, pues tenía fe tanto en los científicos mexicanos como en las autoridades gubernamentales. En parte, sus deseos fueron atendidos, ya que a los ojos de Juan José Saldaña: “además de las exposiciones internacionales, [Porfirio] Díaz apoyó proyectos científicos que le dieran visibilidad internacional a su gobierno o contribuyeran a atraer inversiones extranjeras" (184).

En cuanto a materiales propiamente hemerográficos, la imprenta de Santiago Sierra sacó de sus máquinas La Ilustración Espírita y las ya mencionadas Páginas Literarias..., La Época, La Libertad y El Mundo Científico. ${ }^{12}$ La primera de éstas se publicó de mayo a diciembre de 1877. En total, ocho números correspondientes a los ochos meses de vida. A diferencia de la Imprenta Políglota, de donde salieron los números de enero a abril de La Ilustración, en "Santiago Sierra, Tipógrafo" se vendieron las portadas de cada ejemplar a color y con márgenes garabateados con gran esmero. Era de suponer esta dedicación o detalle en la impresión, puesto que se trataba de una publicación dirigida por el suegro de Sierra, la cual estaba "consagrad[a] exclusivamente a la propaganda del espiritismo", doctrina a la que pertenecía el impresor desde 1871.

La Libertad y La Época, como se ha dicho, fueron diarios de apoyo al gobierno de Porfirio Díaz; así lo demuestran sus programas y subtítulos: Orden y Progreso y "Paz, Justicia y Trabajo". ${ }^{13}$ Al lado de Sierra, Carlos Olaguíbel y Arista (1847-1907), economista,

${ }^{11}$ En realidad, estas opiniones las dio a conocer su autor dos años atrás, pero aún seguían vigentes (véase Sierra, 1875: 1).

${ }^{12}$ En este negocio particular, también se imprimió la primera época de La Bandera Blanca. Semanario Político-Militar, de Industria, Comercio, Artes y Anuncios (ocho números que van del 5 de mayo al 14 de junio de 1877), a cargo de Carlos G. Villasana, editor, propietario y responsable. No he podido consultar esta publicación físicamente debido a que las dos colecciones que registra la base de datos electrónica de la Hemeroteca Nacional de México están extraviadas. Las clasificaciones de dichas misceláneas-colecciones son M123 y M131.

${ }^{13}$ Aunque, propiamente, La Época no llevó subtítulo, el lema "Paz, justicia y trabajo" aparece en varias ocasiones en su programa. La Libertad tuvo, a lo largo de seis años, los subtítulos Periódico Político, Científico y Literario, Periódico Liberal-Conservador y, finalmente, Orden y Progreso. 
político y periodista poblano, dirigió La Época de mayo a diciembre de 1877. Los dos directores propietarios tuvieron en claro que su principal objetivo sería: "trabajar para que el orden se consolide, para que se asegure la justicia y para que el pueblo goce de los beneficios del trabajo honesto y lucrativo" ([Los redactores y directores]: 1). ${ }^{14}$ Esto cobra sentido si se atiende a que el primer número de su publicación vio la luz el 1 de mayo, un día antes de que la Cámara de Diputados declarara por unanimidad de votos "que el señor general Díaz es presidente constitucional de los Estados Unidos Mexicanos para el periodo del $1^{\circ}$ de diciembre de 1876 a 30 de noviembre de 1880" (Caballero: 3). Sólo para recordar, el antecedente de esta atmósfera fue el triunfo del Plan de Tuxtepec y la salida de México del ex presidente Sebastián Lerdo de Tejada rumbo a los Estados Unidos de América.

Aunado a sus textos impregnados de política y en favor de la "estabilidad" o la "paz", La Época ofreció noticias mercantiles, industriales y científicas, por ejemplo, los artículos sobre el tifo y la creación de la Asociación Politécnica Mexicana, firmados por Santiago Sierra. ${ }^{15}$ Otro tipo de escritos, incluidos entre sus páginas, fueron los literarios; allí se dieron a conocer la novela Ma seur feanne (1874, traducida como Mi hermana Fuana) de George Sand, seudónimo de la escritora francesa Amantine Aurore Lucile Dupin (1804-1876), ${ }^{16}$ y el cuento "El gato negro" de Edgar Allan Poe, publicado por entregas semanales y sin créditos al traductor. ${ }^{17}$ Sin mayor aviso que el de: "nuevas ocupaciones, que hemos aceptado por no ser extrañas a las ideas que con tanto cariño abrigamos como buenas para nuestra patria, nos impiden continuar en el trabajo periodístico" (La Redacción: 1), el 30 de diciembre de 1877 los directores de La Época pusieron fin a su labor en pro del bienestar social, sin la posibilidad de que otro equipo de redacción y dirección siguiera su tarea.

\footnotetext{
${ }^{14}$ El 5 de octubre de ese mismo año, Leopoldo Zamora se integró a la redacción. Cabe agregar que Manuel José Sierra Méndez, el verdadero benjamín de los Sierra, publicó en este diario algunos textos.

${ }^{15}$ Me refiero a "El tifo. I" (1877c: 1-2) y "El tifo. II" (1877d: 1-2), los cuales también aparecieron en El Mundo Científico (t. I, 1877f: 17-20).

${ }^{16}$ Escritora que fue censurada por la Iglesia debido a que ésta consideró inmorales sus obras (véase Vieyra, 2008: 159).

${ }^{17}$ Las fechas de las entregas son: $1^{\mathrm{a}}$ ) año I, núm. 24 (27 de mayo de 1877), 2; $2^{\mathrm{a}}$ ) año I, núm. 29 (3 de junio de 1877), 2 y $3^{\text {a }}$ ) año I, núm. 35 (10 de junio de 1877), 2. Debido a que es poco conocida La Época, Sergio Armando Hernández Roura no tuvo la oportunidad de recoger los datos que aquí ofrezco en su tesis de doctorado, titulada "La recepción e influencia de Edgar Allan Poe en México (1859-1922)". También, cabe mencionar que la Biblioteca Miguel Lerdo de Tejada conserva un ejemplar de este periódico y que en la miscelánea 148 del Fondo Reservado de la Hemeroteca Nacional de México se resguardan los números 181 y 195 de este mismo diario, correspondientes al 1 y 19 de diciembre de 1877.
} 


\section{Imprentas e impresores mexicanos en el siglo XIX}

En ese mismo tenor político, el 5 de enero de 1878 comenzó a circular La Libertad (aparente continuación de La Época, si se atiende a que ambos periódicos apoyaron incondicionalmente al poder ejecutivo en turno), cuyo programa advertía del regreso de sus redactores tras poco más de un año fuera de la arena periodística, es decir, cuando aún se encontraban al frente de El Bien Público (1876), periódico de oposición al mandato presidencial de Sebastián Lerdo de Tejada, que vio la luz el mes siguiente de la salida de sus fundadores de El Federalista.

La Libertad estuvo, "desde luego, al lado del hombre que la Constitución llam[ó] a la presidencia de la República"; tuvo siempre en la mira poner su "contingente al servicio de la libertad, del orden, del derecho, que son la verdadera base conservadora de un estado social admitido por la razón”, y llegó, también, "para denunciar como un crimen toda revuelta que se inicie mientras las vías legales estén abiertas" (Los redactores, 1878a: 1).

Específicamente, de los primeros días de enero al 5 de mayo de 1878 (un total de 90 números) dicho diario se imprimió en el establecimiento de Santiago Sierra, al mismo tiempo que éste figuró como su redactor y después como correspondiente, debido a que el taller tipográfico fue cerrado, cuestión en la que ahondaré más adelante. El 9 de mayo de ese año, al cambiar de imprenta - que no de despacho ni de Redacción_-, La Libertad rebajó el costo de su suscripción mensual para toda la República y sustituyó El Mundo Científico - revista creada por Santiago Sierra- por la edición dominical o suplemento casi homónimo El Mundo Científico y Literario (véase Los editores: 1$){ }^{18}$

Lejos de asuntos y temas políticos, El Mundo Científico. Revista de las Ciencias y de sus Aplicaciones a las Artes y a la Industria, Honrada con la Protección Especial del Ministerio de Fomento, según su extenso subtítulo lo expresa, se enfocó en la ciencia y en la industria tanto nacional como extranjera. ${ }^{19}$ Sus dos únicos tomos, del 2 de junio de 1877 al 26 de enero de 1878, contaron con textos de la autoría de su director, Santiago Sierra, y de hombres de ciencia mexicanos, entre ellos, Alfonso Herrera, Vicente Méndez, Santiago Ramírez y Ángel Anguiano, además de artículos científicos en inglés y en francés, traducidos, algunos ex profeso, por el propio Santiago Sierra, como "Recapitulación de las objeciones opuestas a la teoría de la selección natural..." de la última edición inglesa del Origen de las especies de Charles Darwin ( $6^{\text {a }}$ edición. Londres: John Murray, 1876). ${ }^{20}$

Conjeturo que se trata de una traducción de la mano de Santiago Sierra porque, por un lado, al final del primer tomo de su revista científica se dice: "Casi todos los

\footnotetext{
${ }^{18} \mathrm{El}$ anuncio fue reproducido durante dos días más.

${ }^{19}$ Para una revisión más extensa sobre esta revista, véase el artículo de Blanco (403-421).

${ }^{20}$ Véase Darwin (t. I, 11 y 18 de agosto de 1877: 171-174 y 177-183, respectivamente).
} 
artículos y párrafos, que no están comprendidos en este índice, pertenecen a la dirección del periódico, sean originales o traducidos de periódicos extranjeros" (1877h: 279); por otro, como señaló el historiador Roberto Moreno: "sabemos que Santiago Sierra había traducido El origen del hombre y prometió publicarlo, lo que no se realizó por razones que desconocemos" (21). Así pues, se tiene la certeza, amén de los textos prodarwinistas de Santiago y Justo Sierra publicados en los meses de abril a julio de 1875 en El Federalista, que Santiago leía y traducía la obra del naturalista inglés.

Esta labor de divulgación o vulgarización de la ciencia que se llevaba a cabo en México formaba parte de otros proyectos hemerográficos contemporáneos, como $E l$ Minero Mexicano (1873-1879) y El Explorador Minero (1876-1877), en cuyas páginas del primero Santiago Sierra colaboró sólo en cuatro ocasiones, de las cuales destacan sus textos sobre la industria mexicana y la participación de México en el Congreso de Hartford. De El Explorador Minero cabe apuntar que fue dirigido por Santiago Ramírez, uno de los ingenieros más importantes de la época; su despacho y la Redacción estaban ubicados en los bajos del número 16 de la misma calle donde se situaba la imprenta de Sierra.

Gracias al apoyo recibido por Vicente Riva Palacio, en ese momento ministro de Fomento, El Mundo Científico pudo llevar a bien su meta de "consignar los progresos de la ciencia, tanto en sus teorías como en sus aplicaciones prácticas [y señalar] los adelantos que el mundo de la inteligencia verifica en los espacios de la vida científica" (Sierra, 1877e: 1), según se lee en "Las ciencias, las artes y la industria", texto puesto a modo de programa. En este sentido, el director de dicha publicación se había dado a la tarea, desde 1869, de difundir los adelantos de las ciencias, como la meteorología y la astronomía, por medio de novelas y columnas incluidas en el periódico El Federalista (de septiembre de 1874 a agosto de 1875) y en las revistas literarias Violetas (1869) y La Revista de Mérida (1869).

Cabe abrir aquí un paréntesis para hablar brevemente sobre la ciencia y la literatura en la obra de Santiago Sierra Méndez. El 5 de septiembre de 1874, detrás del alias Chilam Balam, comenzó a publicar "Kaleidoscopio", columna dedicada al astrónomo mexicano Francisco Díaz Covarrubias, en la que se propuso: "crear en el Federalista una sección especial, destinada exclusivamente a consignar los progresos de la ciencia, a hacer partícipes a nuestros lectores de todos los adelantos que el mundo de la inteligencia recorre en los espacios de la vida intelectual, de ese inmenso movimiento, producido por todos los impulsos de la humanidad" (Chilam Balam: 1).

En esta misma línea, pero cinco años antes, Sierra también se había comprometido con la tarea de compartir sus conocimientos científicos, pero ahora a través de la literatura; de ahí que escribiera - por entregas en Violetas y en La Revista de Mérida - la novela Viajes por una oreja (1869), en la que puso a dialogar a diferentes autoridades científicas (Alexander von Humboldt, Ludwig Friedrich Kæmtz, Pieter van 


\section{Imprentas e impresores mexicanos en el siglo XIX}

Musschenbroek, Benjamin Franklin y George Louis Leclerc, conde de Buffon) sobre el origen y las características de las trombas marinas.

La literatura, en especial el género novelístico, resultó el canal idóneo a través del cual Santiago Sierra pudo transmitir los conocimientos y avances de la ciencia. Educar al pueblo o a las masas por medio de las novelas fue el estandarte utilizado por la generación de los nacionalistas mexicanos encabezada por Ignacio Manuel Altamirano y, años más tarde, por los seguidores del positivismo. La novela de tema científico puso al alcance de mentes no especializadas asuntos científicos mediante un lenguaje ameno y sencillo (se tenía que suavizar la rigidez de la ciencia, pues no todos eran expertos en el tema); se trató, dentro de las posibilidades del género, de popularizar los tecnicismos que daban fe de los progresos de la ciencia y de la industria en el orbe, así como, en el caso específico de los Viajes extraordinarios de Julio Verne, motivar la imaginación de mundos futuros, de utopías.

A usanza de Santiago Sierra, pero a partir de los años setenta en nuestro país, el ingeniero José Joaquín Arriaga comenzó la labor de escribir y publicar obras literarias-científicas; tómese como ejemplo su novelita La primera semilla, incluida bajo el calificativo de leyenda en el volumen inaugural de la primera época de La Ciencia Recreativa. Publicación Dedicada a los Niños y a las Clases Trabajadoras (1873: 3-36). En ella aparecen seres maravillosos como alegorías de la ciencia, se realizan viajes y aventuras, se llevan a cabo experimentos y se emplea un estilo entretenido y grato, compuesto especialmente para el público infantil de la época. Cierro paréntesis.

Páginas Literarias del Círculo Gustavo Adolfo Bécquer es el quinto material hemerográfico salido de las planchas de "Santiago Sierra, Tipógrafo"; pese a que no he podido localizarlo en ningún repositorio nacional que he consultado ni en catálogos electrónicos de universidades nacionales y extranjeras, gracias a una nota de El Anuario Mexicano (1878) tengo entendido que fue una publicación mensual en $4^{\circ}$ mayor, en “donde pueden verse hermosas poesías de Agustín Cuenca, Juan de Dios Peza, Manuel Caballero, Manuel Gutiérrez Nájera, Benjamín Bolaños y otros, así como notables artículos de Pedro Castera y Anselmo de la Portilla, hijo" (244), quienes fundaron el Círculo Gustavo Adolfo Bécquer a inicios de 1877, y cuyo promotor principal fue el escritor catalán Francisco P. Urgell (véase Perales: 162-163).

La antesala de las rencillas entre Santiago Sierra e Ireneo Paz y, en general, entre La Patria y La Libertad - hasta donde tengo noticia - tuvo lugar con la impresión del primer número del órgano de la sociedad literaria Círculo Gustavo Adolfo Bécquer en el taller tipográfico de Ireneo Paz. El día 13 de mayo de 1877, La Patria acusó al Círculo de no "haber liquidado sus cuentas" y de, aun así, haberse "pasado a otro establecimiento" (la imprenta de Sierra). Por eso, La Patria (Ireneo Paz) tuvo "la necesidad de advertirlo a las otras imprentas para que se libr[ara]n de dificultades ulteriores" (Reyes, 1877a: 3). 
Ante tal imputación, la asociación designó a Agustín F. Cuenca, Benjamín Bolaños y Juan de Dios Peza para que aclararan dicha injuria. Los tres integrantes declararon en una carta lo siguiente: 1) se pagó el costo por impresión del primer número de Páginas Literarias... salido el 1 de abril de la imprenta de Ireneo, pero "fue recibido con general disgusto por la mala litografía, la pésima formación de la planta y las numerosas y notables erratas que plagaban el número", de allí que el Círculo buscara otro impresor; 2) llamaron la atención del público para que comparara las dos versiones, es decir, la de la imprenta de Paz y la del taller de Sierra; 3) se emitió un manifiesto para la prensa nacional, en el que se avisó que el Círculo prescindiría de los servicios de Paz. Este documento salió de la imprenta de Ireneo, puesto que aún no se encontraba en funciones el establecimiento de Santiago Sierra. Lamentablemente, al igual que el primer número de la revista literaria, el manifiesto estaba lleno de erratas, letras rotas y tipos de casta diferente. No obstante, el Círculo decidió pagar el documento en dos partes: la primera al momento y la segunda luego de que se recaudara la cuota extraordinaria de los señores socios; 4) Paz convino en ello, mas cuando el tesorero de la asociación leyó sus recriminaciones, emitidas el día 13 en La Patria, éste se abstuvo de hacer el pago; 5) finalmente, pese a los insultos, se llegó a la resolución de saldar el adeudo correspondiente por la "ínfima cantidad [de] siete pesos" (Cuenca, Bolaños y Peza: 3).

No sobra decir que la mala fama de impresor persiguió al abuelo de Octavio Paz hasta la segunda mitad del siglo pasado. Véase la siguiente crítica severa de Enrique Fernández Ledesma:

fijemos rápidamente la atención en un [libro] de Ireneo Paz — Guadalupe - [1874], impreso en los talleres de "El Padre Cobos". El volumen es la muestra más palpable del empequeñecimiento de entonces, en materia de tipografía y de ornamentación. Se olvidan las buenas tradiciones de mediados de siglo, se pierde el hilo de los limpios menesteres artesanos y se hace una madeja, cada vez más oscura, con los principios de dignidad del oficio. En el libro anotado, todo es lamentable: composición, impresión, litografías (129).

No obstante su deficiente composición, la obra de Paz, Guadalupe, llegó a tener una tercera edición en 1882. No es de sorprender, pues el autor fue el mismo impresor de las tres versiones, el mismo mecenas de su novela mal editada.

En conclusión a las disensiones entre el Círculo y La Patria, este último se limitó a manifestar el 18 de mayo - un día después de darse a conocer la carta aclaratoria de Peza, Bolaños y Cuenca en varios periódicos capitalinos- : "sin mandar saldar su cuenta que por impresiones tiene en este establecimiento, [el Círculo] ha publicado el siguiente artículo que reproducimos con satisfacción por lo que nos honra" (citado en Reyes, 1877b: 3). Esta ocasión no fue la primera ni la última en la que los redactores del diario de Paz utilizaron un tono sarcástico para referirse a sus enemigos de $\mathrm{La} \mathrm{Li}$ - 
bertad, pero sí representó el inicio de varias discrepancias periodísticas (llevadas, por lo general, al terreno de lo personal), que culminaron con el duelo entre Santiago Sierra e Ireneo Paz el 27 de abril de 1880 en las afueras de la Ciudad de México. ${ }^{21}$

Además de revistas y periódicos, el negocio del segundo hijo varón de Justo Sierra O'Reilly se ocupó de materiales bibliográficos de varios géneros: novelas, dictámenes oficiales, ensayos sobre historia, galerías y trabajos científicos, industriales y agrícolas, todos ellos editados de mayo a diciembre de 1877. Sobre asuntos históricos, el mexicano Emilio Castillo Negrete y el español Telésforo García - este último, compañero de redacción de los Sierra en El Bien Público y en La Libertad - publicaron Galería de oradores de México en el siglo XIX y España y los españoles en México, respectivamente. De tema industrial-agrícola, menciono sólo el extenso título Instrucción para el cultivo y preparación del café en la isla de Java / por Munick, inspector del Departamento de Agricultura en Batavi; traducido del inglés para mejora y fomento de este ramo en Guatemala por una señora de aquella República; se imprime de orden del señor don Manuel F. Pavón, ministro de Gobernación y negocios eclesiásticos.

Las novelas La marquesa de Aurebonne de Albéric Second (1817-1887) y Los genios del hogar de Antoine Joseph Napoléon Lespès (1815-1875), mejor conocido por su seudónimo Timothée Trimm, fueron traducidas para el taller de Santiago por Guadalupe Pérez de León, joven cuya identidad quizá corresponda con la de la cantante mexicana de quien se habló ocasionalmente en la prensa capitalina en el último tercio de aquel siglo. Otra mujer traductora que trabajó al lado de Santiago fue su propia esposa: con encargo de La Ilustración Espírita, Tarsila González trasladó del francés al español la "Explicación espírita de los versículos 18 al 20 del capítulo XVIII del Evangelio de san Mateo", que forma parte de la obra Los cuatro evangelios de Jean-Baptiste Roustaing.

De asunto científico, se reprodujo la traducción realizada por el español M. Fernández Llamazares de la Historia de las hormigas (Recherches sur les fourmis indigènes), del entomólogo suizo Pierre Huber (1777-1840). La versión castellana se dio a conocer por primera vez en Madrid en 1867 por la editorial Gaspar y Roig. Ésta no fue la única ocasión en la que Sierra utilizó las traducciones hechas en el otro lado del Atlántico para sus propias publicaciones. Sólo como ejemplo, véase que, en 1874, para la Biblioteca de los Niños, empleó las traducciones de José Sánchez Viedma (o Biedma) de los Cuentos escogidos de los hermanos Grimm (Madrid: Gaspar y Roig, 1867). ${ }^{22}$

${ }^{21}$ Para una revisión más extensa sobre este asunto, véase Rico (2019).

${ }^{22}$ Beatriz Alcubierre Moya señala que la Biblioteca de los Niños, revista en la cual Santiago Sierra tuvo el cargo de jefe de redacción (sólo en los dos tomos de 1874), "fue publicando, de una en una, traducciones casi literales de los cuentos de Grimm, intercambiando tan sólo los nombres de sus personajes por nombres castellanos. Hasta donde sabemos, éste fue el primer contacto de la niñez mexicana con narraciones como 'La cenicienta', 'La caperucita encarnada' o 'Juanito y Margarita' (versión en castellano de 'Hansel y Gretel'), entre otras" (161). Gracias a este dato, 
Propiamente sobre literatura escrita en lengua inglesa, "Santiago Sierra, Tipógrafo" dio a conocer, por vez primera en nuestro país, El endemoniado (The Haunted Man and the Ghost's Bargain, 1848) de Charles Dickens; Aventuras maravillosas; Viaje a la luna; Manuscrito encontrado en una botella; La mentira del globo; ;En el Malestrom! [sic Maelström], y Morella de Edgar Allan Poe. Es de notar que, en la década de los setenta del siglo XIX, amén del taller de Sierra, periódicos como El Eco de Ambos Mundos y El Siglo Diez y Nueve imprimieron David Copperfield (1874) y Cuentos de Navidad (1870), también de Dickens. ${ }^{23}$

A este interés por la traducción de la obra del autor británico se debe agregar el auge de las versiones al español de varias de las novelas de Julio Verne ${ }^{24}$ y de la polémica surgida en torno a las teorías de Darwin desde las tribunas de los positivistas, materialistas, espíritas y hombres de ciencia mexicanos que se enfrentaron cara a cara en El Liceo Hidalgo y en la prensa noticiosa. ${ }^{25}$ La victoria, tal cual lo verifican los actuales planes de estudio, fue de los intelectuales Justo y Santiago Sierra, al exponer, el primero de éstos, los postulados de Darwin en la Escuela Nacional Preparatoria entre 1879 y 1880. Me refiero, en particular, al capítulo "La vida. El hombre", del libro Historia de la antigüedad, de Justo Sierra, dado a conocer, primero, por la Imprenta de José María Sandoval en 1879 y, al año siguiente, por la Imprenta de La Libertad.

El 5 de mayo de 1878 salió por última vez La Libertad de las prensas de Santiago Sierra, quien, ese mismo día, dejó de formar parte directa de la Redacción y fue designado correspondiente. Cuatro días después, este periódico anunció en primera plana algunas reformas, como la disminución del precio de suscripción y la suspensión de El Mundo Científico - cuestiones mencionadas líneas atrás-, pero no se habló sobre el cierre del establecimiento tipográfico de su ex redactor. Tampoco he localizado notas al respecto en el resto de la prensa capitalina.

La razón del cese de esta imprenta se debe a que el 11 de abril de aquel año Santiago Sierra, en calidad de secretario de la Legación Mexicana de América del

pude localizar el cuento de "Tom Pouce" ("Pulgarcito" en el mundo hispanoamericano) entre las páginas de la Biblioteca... ("Cuentos de los hermanos Grimm. Tom Pouce": 23-30). Pese a que no hubo créditos al traductor, la versión de esta publicación es casi idéntica — salvo algunos usos de puntuación - a la del español José Sánchez Viedma. Véanse los siguientes casos de laísmos y leísmos, tan frecuentes en la región madrileña: "mientras su mujer hilaba a su lado, él la decía — ¡Cuánto siento no tener hijos! [...] —Sí, respondió su mujer suspirando, yo quedaría contenta, aunque no tuviésemos más que uno solo tan grande como el dedo pulgar, y le querríamos con todo nuestro corazón" ("Cuentos de los hermanos...": 24; las negritas son mías).

${ }^{23}$ La Biblioteca Nacional de México conserva ejemplares de estos dos libros.

${ }^{24}$ Hace tres años, la investigadora Lilia Vieyra Sánchez publicó su libro Inéditos del siglo XIX. Escritores, traductores, periodistas, editores y empresas editoriales, en el que dedica un capítulo a la recepción - traducciones y comentarios críticos - de la obra de Julio Verne en México (1872-1905).

${ }^{25}$ Acerca de este asunto, véanse Moreno (17-42 y 167-169) y Leyva (135-158). 


\section{Imprentas e impresores mexicanos en el siglo XIX}

Sur, junto con Leonardo López Portillo, ministro plenipotenciario, y Anselmo de la Portilla (hijo), oficial traductor o segundo secretario, se embarcaron rumbo a Santiago de Chile para cumplir con sus funciones diplomáticas. ${ }^{26}$

El local de "Santiago Sierra, Tipógrafo" fue ocupado por La Libertad, como domicilio de su despacho y Redacción, hasta el jueves 13 de junio de 1878. Sin tener aún datos confiables sobre qué ocurrió con el inmueble y con la maquinaria del taller tipográfico luego de su cierre (seguramente, las prensas, los tipos y otros objetos fueron primero embodegados y después comprados por la Imprenta de La Libertad, propiedad de Justo Sierra, cuyo funcionamiento comenzó a finales del mes de enero de 1880), sólo he encontrado que la imprenta de Ireneo Paz se instaló allí a finales de 1878, según consta en la página uno del diario La Patria con fecha del 31 de diciembre: "Es cierto que hemos cambiado las oficinas de La Patria a la calle de las Escalerillas núm. 7, en donde estamos a las órdenes de ustedes" (Los redactores, 1878b: 1).

Tras su regreso de la capital chilena en octubre de 1879, Santiago Sierra volvió a fungir como oficial $1^{\circ}$ y como redactor de La Libertad, pero no retornó a su labor como impresor. Es probable que aquellas ocupaciones periodísticas y políticas obstaculizaran la reapertura de su tipografía. Quizá también el ex impresor halló un mercado más competitivo o no encontró un local con las condiciones necesarias para albergar un taller lo suficientemente grande que imprimiera todo tipo de materiales, como tiempo atrás lo hizo. Tampoco hay indicios para pensar que la reapertura no se llevó a cabo por razones monetarias: había dinero en las arcas de los Sierra y en los bolsillos de sus amistades políticas. Además, no se olvide que, para esos años, la Imprenta de La Libertad ya estaba en funcionamiento: ¿para qué, entonces, competir entre familiares tan queridos?

\section{A modo de conclusión}

Como se ha visto, pese a la breve vida de esta empresa tipográfica, Santiago Sierra tuvo, durante abril de 1877 y mayo de 1878, la clara intención de llegar a diferentes tipos de lectores y compradores: desde los más comunes o habituales de la época, que acudían a una imprenta por un simple recibo, una factura o una tarjeta de visita, hasta aquellos grupos de intelectuales como el Círculo Literario Gustavo Adolfo Bécquer, cuyos integrantes fueron amigos cercanos del segundo hijo varón de Justo Sierra O'Reilly.

\footnotetext{
${ }^{26}$ Santiago Sierra regresó a la Secretaría de Relaciones Exteriores luego de desempeñar los cargos de escribiente segundo (interino) de la sección de América y escribiente tercero de la sección de Europa entre 1874 y 1876 (cfr. Wu: 13).
} 
En términos generales, la imprenta se ocupó de materiales primarios o de primer orden (libros, manuales, periódicos, revistas, etc.), que representaban mayores costos y tiempo de producción, pero mejores ganancias y más prestigio cultural, y de materiales secundarios o de segundo orden, como tarjetas de visita, libranzas, estados, etcétera, que se imprimían en menor tiempo que los primeros y eran más solicitados por el grueso de la población mexicana de la capital.

La diversidad de las obras impresas en "Santiago Sierra, Tipógrafo" también muestra los intereses de su propietario en distintos campos del saber humano: la ciencia, la industria, la literatura, la política, la historia y la instrucción pública, sólo por mencionar algunos. Al respecto, concuerdo con las siguientes palabras de Roger Chartier: "En la década de 1830 se fija la figura del editor que aún conocemos. Se trata de una profesión de naturaleza intelectual y comercial que apunta a buscar textos, a descubrir autores, a vincularlos con la casa editora, a controlar el proceso que va desde la impresión hasta su difusión" (37).

Santiago Sierra, por tanto, se posicionó como un editor forjador de la historia cultural y científica y como un intelectual interesado en las novedades literarias y científicas de Europa y de América. Si bien empleó a un par de traductoras, cajistas y formadores, las faenas de creación y selección de textos fueron realizadas con sus manos y cabeza. Sabía muy bien quiénes eran los autores y las obras en boga, pero sabía aún mejor quiénes estarían algún día en las historias de la ciencia y las letras mundiales.

En torno a las obras literarias escritas en inglés y francés, el taller de Santiago Sierra estuvo al tanto de las publicaciones recientes y de los autores consagrados: en unos casos, se optó por traducirlos ex profeso y, en otros, por acudir a versiones y ediciones españolas, cambiando únicamente algunos elementos tipográficos, como sucedió con los cuentos de los hermanos Grimm, aludidos en párrafos anteriores. Ante esta labor, si bien el taller puede ser considerado de menor importancia frente a los de Ignacio Cumplido y Francisco Díaz de León y Santiago White (por el poco lapso de vida y la cantidad de productos), el microempresario Santiago, desde un trabajo casi individual, ayudó a formar y divulgar, en nuestro país, el canon de autores y obras literarias en inglés (Dickens y Poe) y el canon de hombres de ciencia (Darwin, por citar un solo ejemplo).

Es probable, además, que de no haber aceptado el viaje diplomático a América del Sur en la primera mitad de 1878, como se anunció líneas atrás, y de no haber fallecido a finales de 1880, Santiago Sierra se habría convertido en uno de los impresores más socorridos tanto por asociaciones culturales y científicas como por miembros de la política dominante. Porfirio Díaz, a quien se defendió a capa y espada en La Época y en La Libertad, brindó su apoyo a los hermanos Justo y Manuel José Sierra Méndez durante sus más de treinta años en la silla presidencial.

Así pues, quedan aún varios vacíos y lagunas por ser llenados en torno a la vida, obra y oficios del segundo hijo varón de Justo Sierra O’Relly. Por ello, es importante 
continuar la labor de consulta y lectura de su obra dispersa en poco más de una veintena de revistas y periódicos capitalinos y foráneos, así como la localización, en caso de que existieran, de su epistolario y su diario.

\section{Bibliografía}

Aguilar, Ignacio

"Gacetilla. Nombramiento", en La Voz de México, tomo VIII, número 195 (25 de agosto de 1877), 3.

Alcubierre Moya, Beatriz

Ciudadanos del futuro: una historia de las publicaciones para niños en el siglo XIX mexicano. México: El Colegio de México, Centro de Estudios Históricos/Universidad Autónoma del Estado de Morelos, 2010.

El Anuario Mexicano: recopilación de los acontecimientos más notables en la política, la literatura y el comercio del año de 1877. Obra importante que aparecerá el mes de enero de cada año, dirigida por Filomeno Mata

Tomo I. México: Tipografía Literaria, 1878.

Arriaga, José Joaquín

"La primera semilla", en La Ciencia Recreativa. Publicación Dedicada a los Niños y a las Clases Trabajadoras. Primera época. México: Imprenta de José María Aguilar Ortiz, 1873, 3-36.

BABLOt, Alfredo

"El Federalista. Cambio de redacción", en El Federalista, tomo VII, número 1741 (15 de julio de 1876a), 1.

“Lo que pasa. El Siglo XIX”, en El Federalista, tomo VII, número 1741 (15 de julio de 1876b), 2.

"El Federalista. Breves palabras", en El Federalista, tomo VII, número 1742 (18 de julio de 1876c), 1 .

Biblioteca de los Niños. Revista Quincenal para Enseñanza y Recreo de la Niñez

México: Alfredo J. Bablot y Peña y Román Araujo, 1874, 3 tomos.

BLanco, María del Pilar

"Mexican Modernity, Science Magazines, and Scientific Personality: Santiago Sierra's El Mundo Científico (1877-78)", en Modernism/Modernity, volumen 23, número 2 (abril de 2016), 403-421.

Caballero, Manuel

"A última hora", en La Época, año I, número 3 (3 de mayo de 1877), 3. 


\section{Chartier, Roger}

Las revoluciones de la cultura escrita. Diálogos e intervenciones. Barcelona: Gedisa, 2000.

Chilam Balam [Santiago Sierra]

"Kaleidoscopio. Al eminente astrónomo don Francisco Díaz Covarrubias. Homenaje a las ciencias naturales", en El Federalista, tomo V, número 1279 (5 de septiembre de 1874), 1.

Cuenca, Agustín F., Benjamín Bolaños y Juan de Dios Peza

"Remitidos. La Patria y el 'Círculo Gustavo A. Bécquer”, en La Época, año I, número 15 (17 de mayo de 1877), 3.

"Cuentos de los hermanos Grimm. Tom Pouce"

Biblioteca de los Niños. Revista Quincenal para Instrucción y Recreo de la Niñez, tomo III (1 de abril de 1875), 23-30.

Curiel, Guadalupe y Miguel Ángel CASTro (coordinadores)

Obras monográficas mexicanas del siglo XIX en la Biblioteca Nacional de México: 1822-1900. México: Universidad Nacional Autónoma de México, Coordinación de Humanidades, Instituto de Investigaciones Bibliográficas, 1997.

DARwin, Charles

"M. Charles Darwin, de la Sociedad Real de Londres. Origen de las especies", en El Mundo Científico, tomo I (11 y 18 de agosto de 1877), 171-174 y 177-183, respectivamente.

Directorio telefónico de la Ciudad de México. Año de 1891

Edición facsimilar. México: Centro de Estudios de Historia de México Condumex, 1991.

LOS EDITORES

“Interesante”, en La Libertad, año I, número 100 (9 de mayo de 1878), 1.

Fernández Ledesma, Enrique

Historia crítica de la tipografia de la Ciudad de México. Facsímile de la edición de 1934-1935 (Ediciones del Palacio de Bellas Artes). México: Universidad Nacional Autónoma de México, Instituto de Investigaciones Bibliográficas, 1991.

Giron BarThe, Nicole

"El entorno editorial de los grandes empresarios culturales: impresores chicos y no tan chicos en la Ciudad de México", en Laura Beatriz Suárez de la Torre (coordinadora). Empresa y cultura en tinta y papel, 1800-1860. México: Instituto Mora, 2001, 51-59.

Hernández Roura, Sergio Armando

"La recepción e influencia de Edgar Allan Poe en México (1859-1922)". Tesis de doctorado. Barcelona: Universitat Autònoma de Barcelona, 2016.

JAMAPa [Rafael de ZaYas EnRíQuez]

"Los hombres del Federalista. Santiago Sierra", en El Eco de Ambos Mundos. Diario de Política, año V, número 493 (11 de agosto de 1874), 1. 
Leal Miranda, Edith

"Francisco Díaz de León: el editor de la República de las Letras. Una lectura desde la teoría de las generaciones", en Daniar Chávez y Fernando Curiel (coordinadores). Ciudades generacionales. México: Universidad Nacional Autónoma de México, Instituto de Investigaciones Bibliográficas, 25-43.

LeYva, José Mariano

El ocaso de los espiritus. El espiritismo en México en el siglo XIX. México: Cal y Arena, 2005.

Llanos y Alcaraz, Adolfo

"Gacetilla. Establecimiento tipográfico de Santiago Sierra", en La Colonia Española, año IV, número 127 (25 de abril de 1877), 3.

Morales, V.

"Gacetilla. Chano Sierra", en El Monitor Republicano, 5a época, año XXVII, número 95 (21 de abril de 1877), 3 .

Moreno, Roberto

La polémica del darwinismo en México: siglo XIX. Testimonios. $2^{a}$ edición. México: Universidad Nacional Autónoma de México, Instituto de Investigaciones Históricas, 1989 (Historia de la Ciencia y la Tecnología, 1).

Perales Ojeda, Alicia

Las asociaciones literarias mexicanas. Tomos I y II. México: Universidad Nacional Autónoma de México, Coordinación de Humanidades, Instituto de Investigaciones Filológicas, 2000.

Real Academia Española

Diccionario de la lengua castellana. $11^{\text {a }}$ edición. Madrid: Imprenta de Manuel Rivadeneyra, 1869.

La REDACGión

"Despedida", en La Época, año I, número 204 (30 de diciembre de 1877), 1.

Los redactores [Santiago y Justo Sierra, Francisco G. Cosmes, Eduardo Garay y Telésforo GARCíA]

"Programa", en La Libertad, año I, número 1 (5 de enero de 1878a), 1.

LOS REDACTORES

"Editorial. A nuestros suscriptores", en La Patria, año II, número 532 (31 de diciembre de 1878b), 1 .

[LOS REDACTORES Y DIRECTORES]

"Programa", en La Época, año I, número 1 (1 de mayo de 1877), 1.

Reyes, A.

"Sucesos del día. El Círculo Gustavo A. Becker [sic]", en La Patria, tomo I, número 47 (13 de mayo de 1877a), 3 . 


\section{$\dashv$ Jonathan Rico Alonso}

"Sucesos del día. El Círculo Bécquer", en La Patria, tomo I, número 5 (18 de mayo de 1877b), 3 .

“Sucesos del día. Oficial 1”, en La Patria, tomo I, número 134 (26 de agosto de 1877c), 3.

\section{Rico Alonso, Jonathan}

"Rescate, estudio y edición crítica de Viajes por una oreja (1869), de Santiago Sierra". Tesis de maestría. San Luis Potosí: El Colegio de San Luis, 2019.

Ruiz, Pedro

“Gacetilla. Oficial 1"”, en El Pájaro Verde, año XVI, número 225 (28 de agosto de 1877), 1.

SALDAÑa, Juan José

"La ciencia y la política en México (1850-1911)", en Ruy Pérez Tamayo (coordinador). Historia de la ciencia en México. México: Fondo de Cultura Económica/Consejo Nacional para la Cultura y las Artes, 2010, 120-199 (Biblioteca Mexicana. Serie Historia y Antropología).

SIERRA, Santiago

"El 'Federalista", en El Federalista, tomo V [sic VI], número 1526 (3 de septiembre de 1875), 1.

[Sin firma] "Avisos. Santiago Sierra, Tipógrafo", en La Época, año I, número 1 (1 de mayo de 1877a), 4.

"Sección científica. El natalicio de Hahnemann. Discurso pronunciado por Santiago Sierra", en La Ilustración Espírita, año VIII, número 5 (1 de mayo de 1877b), 147-149.

“El tifo. I”, en La Época, año I, número 4 (4 de mayo de 1877c), 1-2.

“El tifo. II”, en La Época, año I, número 5 (5 de mayo de 1877d), 1-2.

[Sin firma] "Las ciencias, las artes y la industria", en El Mundo Científico, tomo I, número 1 (2 de junio de $1877 \mathrm{e}), 1$.

“El tifo. I y II”, en El Mundo Cientifico, tomo I (2 de junio de 1877f), 17-20.

[Sin firma] "Libros de texto", en El Mundo Científico, tomo I (4 de agosto de 1877g), 150.

[Sin firma] "Nota", en El Mundo Científico, tomo I (septiembre de 1877h), 279.

Sosa, Francisco

Biografias de mexicanos distinguidos. México: Oficina Tipográfica de la Secretaría de Fomento, 1884.

Vieyra SÁnchez, Lilia

La Voz de México (1870-1875): la prensa católica y la reorganización conservadora. México: Univer- 
sidad Nacional Autónoma de México, Instituto de Investigaciones Bibliográficas/Instituto Nacional de Antropología e Historia, 2008.

Inéditos del siglo XIX. Escritores, traductores, periodistas, editores y empresas editoriales. México: Gobierno del Estado de México, Secretaría de Cultura, 2015 (Raíz del Hombre).

Wu Brading, Celia

Santiago Sierra: la diplomacia mexicana en América del Sur y la Guerra del Pacifico 1878-1879. Presentación y compilación de Celia Wu Brading. México: Secretaría de Relaciones Exteriores, Dirección General del Acervo Histórico Diplomático, 1995. 